\title{
Potential use of Thermoelectric Generator Device for Air Conditioning System
}

\author{
Pedro M. Peralta Trinidad ${ }^{1}$, Gerardo Carbajal ${ }^{1}$ \\ ${ }^{1}$ Universidad del Turabo, Puerto Rico, pperalta.engi@gmail.com, gcarbajal1@suagm.edu
}

\begin{abstract}
For this research a thermoelectric array was designed and used to experimentally investigate the energy consumption of this device may cause a cooling process in the hot fluid. For this purpose an experimental setup was designed in which a square channel allows the fluid flow of cold and hot air. Hot air was pumped at the bottom section and cold at the top section; the two fluids were separated by a wall. The heat source had a maximum capacity of $1850 \mathrm{~W}$ and the electrical loads used in the experiments were in the range between $390 \Omega$ and $760 \Omega$. It was found that the temperature difference between the inlet and outlet of the hot air was affected by the application of an electrical load. The numerical solution indicates that this system behaves different that a typical counter flow heat exchanger.
\end{abstract}

Keywords - energy, air conditioning system, thermoelectric, temperature, flow

Digital Object Identifier (DOI): http://dx.doi.org/10.18687/LACCEI2015.1.1.234

ISBN: 13 978-0-9822896-8-6

ISSN: $2414-6668$

$1^{\text {th }}$ LACCEI Annual International Conference: “Engineering Education Facing the Grand Challenges, What Are We Doing?” July 29-31, 2015, Santo Domingo, Dominican Republic ISBN: 13 978-0-9822896-8-6

ISSN: 2414-6668

DOI: http://dx.doi.org/10.18687/LACCEI2015.1.1.234 


\title{
Potential use of Thermoelectric Generator Device for Air Conditioning System
}

\author{
Pedro M. Peralta Trinidad, Gerardo Carbajal \\ UniversidaddelTurabo,Puerto Rico,pperalta.engi@gmail.com,gcarbajal1@suagm.edu
}

\begin{abstract}
For this research a thermoelectric array was designed and used to experimentally investigate the energy consumption of this device may cause a cooling process in the hot fluid. For this purpose an experimental setup was designed in which a square channel allows the fluid flow of cold and hot air. Hot air was pumped at the bottom section and cold at the top section; the two fluids were separated by a wall. The heat source had a maximum capacity of $1850 \mathrm{~W}$ and the electrical loads used in the experiments were in the range between $390 \Omega$ and $760 \Omega$. It was found that the temperature difference between the inlet and outlet of the hot air was affected by the application of an electrical load. The numerical solution indicates that this system behaves different that a typical counter flow heat exchanger.
\end{abstract}

\section{NOMENCLATURE}

ZT Figure of merit

$\mathrm{S} \quad$ Seebeck coefficient, $m v /{ }^{\circ} \mathrm{C}$

T Absolute Temperature, $K$

$\mathrm{k}$ Thermal conductivity compose of lattice, $\mathrm{W} /(m \cdot K)$

$\mathrm{k}_{p} \quad$ Thermal conductivity, $\mathrm{W} /(m \cdot K)$

$\mathrm{k}_{e} \quad$ Electronic thermal conductivity, $\mathrm{W} /(m \cdot K)$

$\mathrm{Q}_{H} \quad$ Hot side thermal energy, $W$

$\mathrm{Q}_{L} \quad$ Cold side thermal energy, $W$

$\mathrm{W}_{e} \quad$ Idealized produced work, $W$

$\Delta T_{H C} \quad$ Average temperature difference: hot and cold surface

TEG Thermoelectric Generator

$\Delta T_{H} \quad$ Temperature difference: inlet and outlet of the hot air

$\begin{array}{ll} & \text { Greek Symbols } \\ \sigma & \text { Electrical conductivity, } S / m \\ \Delta & \text { Difference } \\ \Omega & \text { Ohms }\end{array}$

$\begin{array}{ll} & \text { SubSCRIPT } \\ \mathrm{p} & \text { phonon } \\ \mathrm{e} & \text { Electrical } \\ \mathrm{H} & \text { Hot } \\ \mathrm{L} & \text { Load } \\ \mathrm{C} & \text { Cold }\end{array}$

\section{INTRODUCTION}

Since 1990s interest in thermoelectric energy conversion was renewed, first in potential refrigeration applications and subsequently in power generation [1]. These devices are very promising for its capacity of converting calorific energy into electrical energy, in a direct and passive way. Because many of the efficiency problems of processes are due to energy being wasted as heat these devices has a great application as regenerators. Recovering a small quantity of this waste heat $(5-10 \%)$ can increase the system efficiency and mitigate the environmental impacts of fossil fuel based power generation [2].

Thermoelectric devices are capable of conducting electrical current when a temperature difference is applied due to the Seebeck effect. This effect was discovered by Thomas Seebeck who observed that when a temperature difference was applied to two dissimilar materials an electrical current was generated. The schematics of a simple thermoelectric generator, taken from reference [3], is shown in Fig1 Heat is transferred from a high-temperature source to the hot junction in the amount of $Q_{H}$, and it is rejected to a low-temperature sink from the cold junction in the amount of $Q_{L}$ [3]. The difference between these two quantities is the net electrical work produced, that is, $W_{e}=Q_{H}-Q_{L}$ [3]. This is assuming that all the heat is converted into electrical energy, also meaning that the efficiency of the system is the Carnot's efficiency.

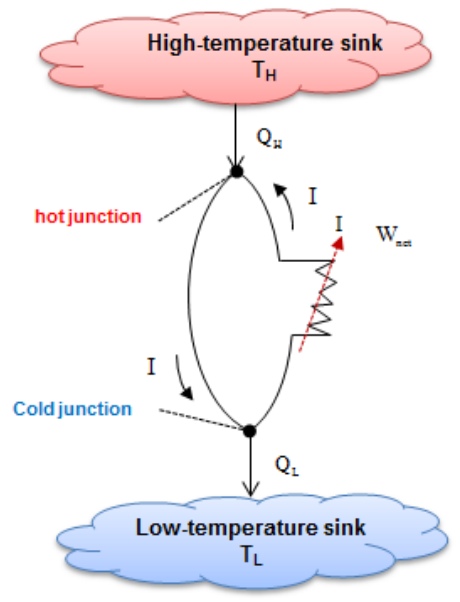

Figure 1: Schematic of a simple power generator [3]

$1^{\text {th }}$ LACCEI Annual International Conference: “Engineering Education Facing the Grand Challenges, What Are We Doing?” 


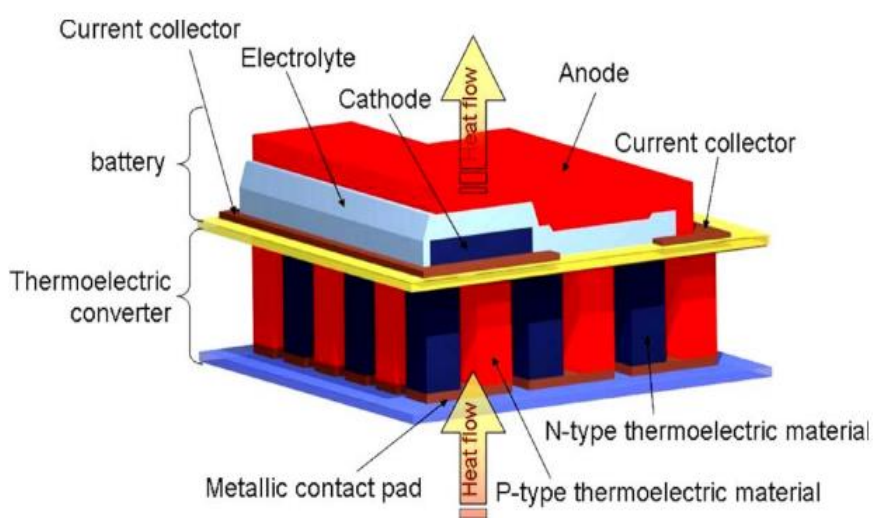

Figure 2: Artwork of a thermoelectric microsystem [4]

Shown in Fig (2) is an example of how a thermoelectric physically works. "If the junctions at the bottom are heated and those at the top are cooled (producing a temperature differential), electron/hole pairs will be created at the hot end and absorb heat in the process. The pairs recombine and reject heat at the cold edges. A voltage potential, the Seebeck voltage, which drives the hole/electron flow, is created by the temperature difference between the hot and cold edges of the thermoelectric elements. The net voltage appears across the bottom of the thermoelectric element legs" [4].

When analyzing the performance of a thermoelectric the Carnot's efficiency can only be taken as a reference of the maximum performance of the device. The efficiency is measured by the figure of merit:

$$
Z T=\frac{S^{2} \sigma}{k} T
$$

Where: $\mathrm{S}$ is the Seebeck coefficient, $\sigma$ is the electrical conductivity, $S^{2} \sigma$ is the power factor, and $k=k_{p}+k_{e}$ is the thermal conductivity composed of lattice, i.e., phonic, thermal conuctivity $k_{p}$, and electronic thermal conductivity $k_{e}[1,2]$. An idealized thermoelectric material would have a large power factor and a small thermal conductivity. This is challenging as these requirements are often contradictory to each other [1].

Progress on enhancing thermoelectric materials properties is crucial for the developing of sustainable conversion of heat to electrical energy. Currently, Peltier cooling devices on the market are almost exclusively based on $\mathrm{Bi}_{2} \mathrm{Te}_{3}$ with a $\mathrm{ZT}$ value around $1[1]$.

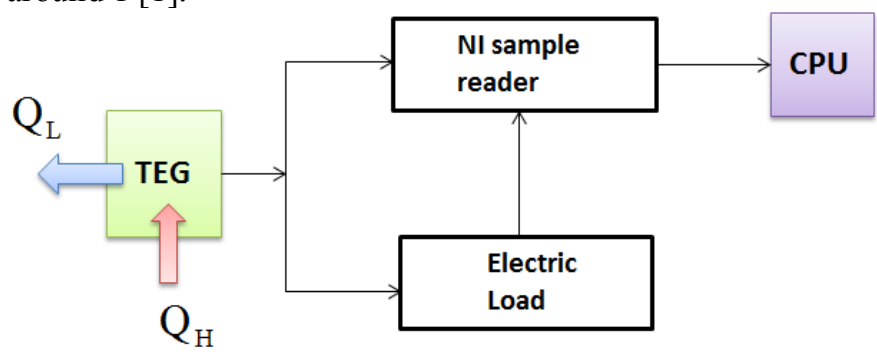

Figure 3: Diagram of experimental set up

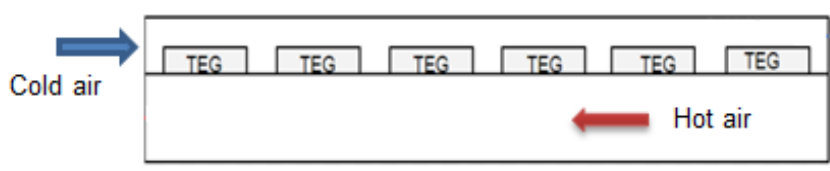

Figure 4: schematic of experimental procedure

\section{FOCUS OF THE EXPERIMENT}

The focus for this experiment is to determine whether or not $\Delta \mathrm{T}_{\mathrm{H}}$ increases when heat energy is converted into electric energy by the TEG. Two conditions are tested, when the TEG has no electric load applied and when electric load is applied. The $\Delta \mathrm{T}_{\mathrm{H}}$ is then compared for the two conditions.

\section{EXPERIMENTAL SET UP}

In Fig (3) is shown the experimental set up. The block named TEG represents the thermoelectric generator, where heat is entering at the rate of $\mathrm{Q}_{\mathrm{H}}$ and heat is removed from the cold side at the rate of $\mathrm{Q}_{\mathrm{L}}$. The TEG was connected to a National Instrument (NI) device to acquire the data, using a NI-9305 the voltage was read and using a NI-9313 the temperature was measured respectively. Parallel to the connection to NI-DAQ the TEG was connected to an electric load.

The signals were processed by the computer using $L a b$ View. The heat input applied to the TEG was varied from $40 \%$ to $100 \%$, at a rate of $20 \%$, the total capacity of the heat source was $1850 \mathrm{~W}$. The test was conducted, at steady state, by running the experiment without the electric load and after a minute the load was applied for another minute. This was made with two different resistance, $390 \Omega$ and $760 \Omega$. In Fig.4 is shown how the experiment was conducted, hot air was injected at the bottom channel and cold air at the upper. With this fluid flow process the desired temperature gradient $\left(\Delta T_{H-C}\right)$ was achieved and maintained.

\section{NUMERICAL SIMULATION}

A numerical simulation was conducted to analyze the heat transfer process across the thermoelectric during the counter flow of cold and hot air. The governing equations used in the simulation were the continuity, momentum and energy equation respectively. For the fluid flow the equation are listed as follows:

Continuity equation:

$\nabla \cdot \vec{V}=0$

Momentum equation:

$\nabla \cdot(\rho \vec{V} \vec{V})=\rho \vec{g}-\nabla P+\mu \nabla^{2} \vec{V}$

Energy equation:

$\rho C_{p} \vec{V} \cdot \nabla T=\nabla \cdot(k \nabla T)$

For the solid material, the energy equation is expressed as:

$0=\nabla \cdot(k \nabla T)$

The main assumptions in the present study are: steady state condition, negligible viscous dissipation terms, and

$1^{\text {th }}$ LACCEI Annual International Conference: "Engineering Education Facing the Grand Challenges, What Are We Doing?"

July 29-31, 2015, Santo Domingo, Dominican Republic 
constant properties of the fluid. In the present study it was assumed incompressible flow because the Mach of the air flow was less than 0.3 .

Hot and cold air represents the typical fluids that enter and leaves an air conditioning system (AC). The hot air resembles the warm temperature of the outside ambient air in a typical summer season to be conditioned; the cold air is the exhaust air from the AC system, see Fig (5). The fundamental objective of this analysis is to investigate how much useful energy can be obtained from the cold air by the use of thermoelectric devices. Due to the limitation of spacing in the experimental part, the air was heated to a maximum value of 108 degree Celsius. The cold fluid inlet was 26 degree Celsius. A counter flow configuration was applied between the hot and cold fluid.

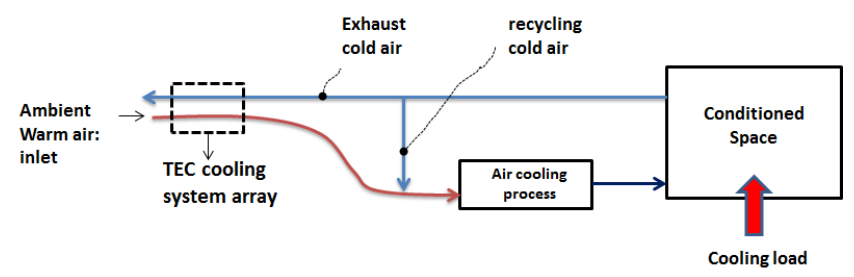

Figure 5: The TEC installed in an AC system

The hot fluid entered at a uniform air speed of $0.2 \mathrm{~m} / \mathrm{s}$, and the cold fluid entered at a uniform speed of $0.5 \mathrm{~m} / \mathrm{s}$. The thermal material to simulate the thermoelectric was Bismuth Telluride. The physical dimensions of the simulation are represented in Fig (6). The boundary conditions are indicated as follows: no slip condition on the wall, the top and bottom surface were assumed as adiabatic surfaces. Foam material was used between the thermoelectric in accordance with the experimental setup.

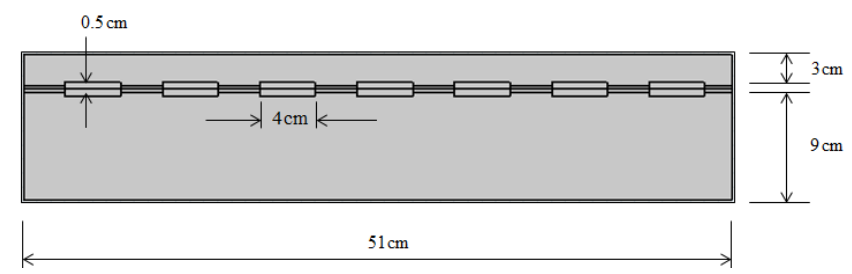

Figure 6: main dimensions of the array and channels

\section{RESULTS AND DISCUSSION}

A total of 8 tests were performed as explained in the experimental procedure. Only two of the plots are shown in this section to explain the results, but all the data obtained is presented in table 1 .

\section{A. TEST AT $40 \%$ OF THE POWER WITH ELECTRIC RESISTANCE OF 390 OHMS}

The comparison of the temperature difference and the voltage is shown in Fig (7). For the test there was no load applied from sample time between $45.2 s<t<112 s$ and the load was applied from $112 s<t<177 s$. The $\Delta T_{H-C}$ at steady state was about $21^{\circ} \mathrm{C}$. When the electric load is applied there was voltage drop and $\Delta T_{H}$ changes in average from $1.23^{\circ} \mathrm{C}$ to $1.35^{\circ} \mathrm{C}$.
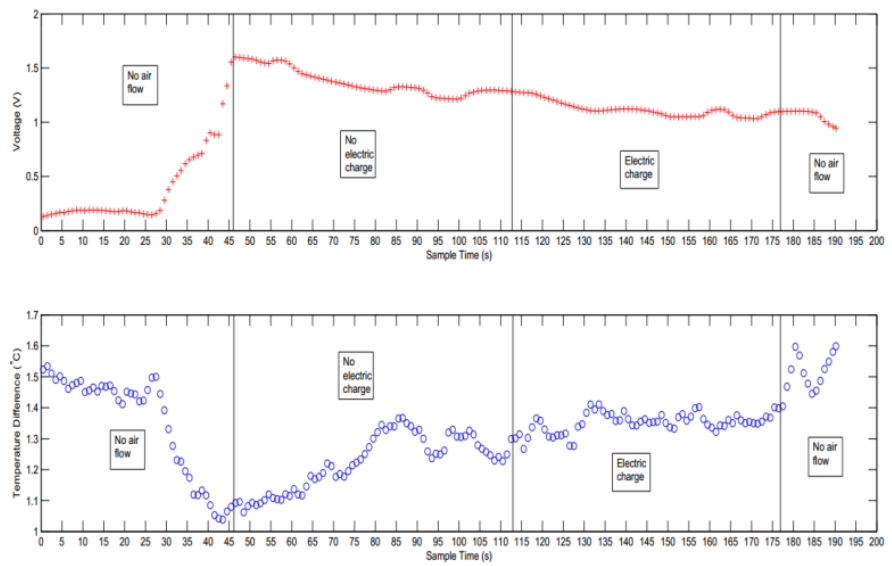

Figure 7: Voltage and temperature difference against sample time for heat at $40 \%$ power capacity and $3900 \mathrm{hms}$.

B. TEST AT $100 \%$ OF THE POWER WITH ELECTRIC RESISTANCE OF 390 OHMS

The comparison of the temperature difference $\left(\Delta T_{H-C}\right)$ and the voltage is shown in Fig (8). For this test there was no load applied from sample time between $70 s<t<110 s$ and the load was applied from $120 \mathrm{~s}<t<180 \mathrm{~s}$. The $\Delta T_{H-C}$ at steady state was about $73^{\circ} \mathrm{C}$. When the electric load was applied a voltage drop occurs, and $\Delta T_{H}$ changes in average from $2.11^{\circ} \mathrm{C}$ to $2.02^{\circ} \mathrm{C}$.
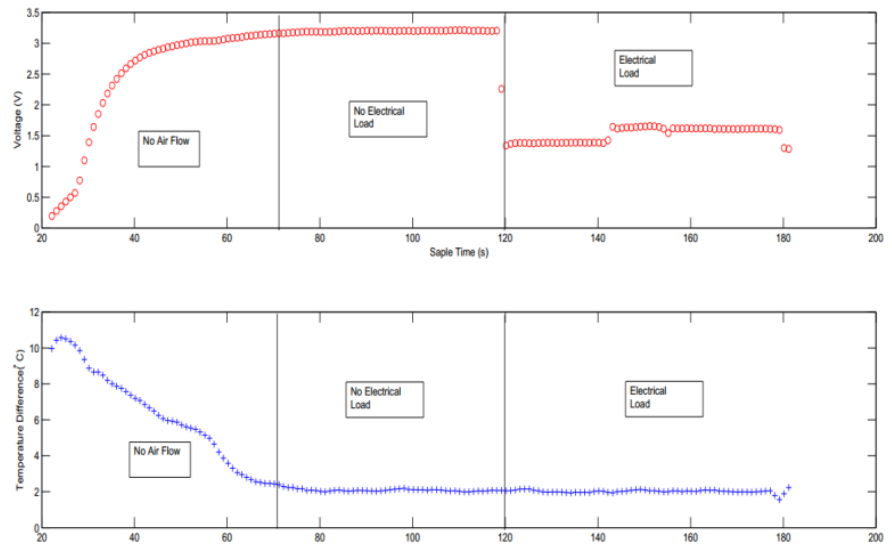

Figure 8: Voltage and temperature difference against sample time for the heat at $100 \%$ power capacity and $360 \mathrm{ohms}$.

\section{SUMmary}

In table 1 is shown the values of the temperature gradient for all the tests performed in the experimental part. Here it can be seen that for some points the temperature gradient increases and at other decreases. This reduction in temperature gradient may be caused by a transient process of the system.

13 ${ }^{\text {th }}$ LACCEI Annual International Conference: "Engineering Education Facing the Grand Challenges, What Are We Doing?" 
Table 1: Data obtained from tests

\begin{tabular}{l|lr}
\hline Test & $\Delta T_{H 1}$ & $\Delta T_{H 2}$ \\
\hline $40 \%, 390 \Omega$ & $1.23^{\circ} \mathrm{C}$ & $1.35^{\circ} \mathrm{C}$ \\
$60 \%, 390 \Omega$ & $2.51^{\circ} \mathrm{C}$ & $2.53^{\circ} \mathrm{C}$ \\
$80 \%, 390 \Omega$ & $6.22^{\circ} \mathrm{C}$ & $6.02^{\circ} \mathrm{C}$ \\
$100 \%, 390 \Omega$ & $2.11^{\circ} \mathrm{C}$ & $2.02^{\circ} \mathrm{C}$ \\
$40 \%, 760 \Omega$ & $2.64^{\circ} \mathrm{C}$ & $2.72^{\circ} \mathrm{C}$ \\
$60 \%, 760 \Omega$ & $3.39^{\circ} \mathrm{C}$ & $3.61^{\circ} \mathrm{C}$ \\
$80 \%, 760 \Omega$ & $3.58^{\circ} \mathrm{C}$ & $1.28^{\circ} \mathrm{C}$ \\
$100 \%, 760 \Omega$ & $1.90^{\circ} \mathrm{C}$ & $1.62^{\circ} \mathrm{C}$ \\
\hline
\end{tabular}

\section{NuMERICAL RESUlTS}

Figure 9 represents the different locations where the temperature profile was checked. The linear plot for the temperature across the thermoelectric shown is depicted in Figure (10).

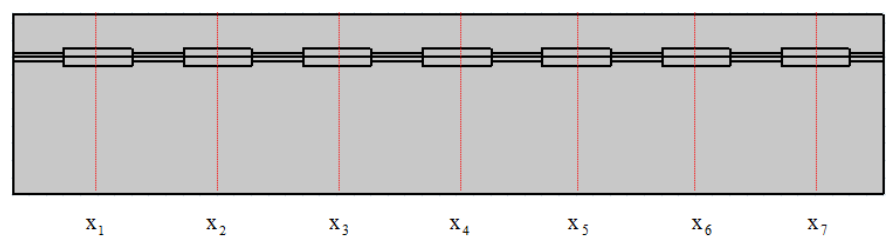

Figure 9: Representation of the lines for linear plot of temperatures.

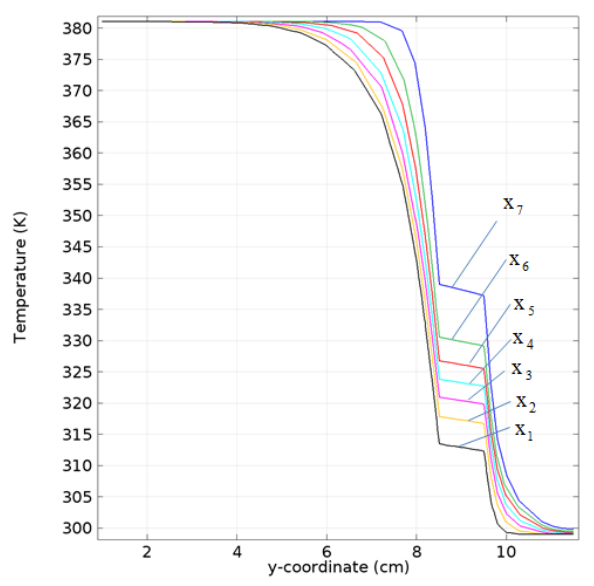

Figure 10: Linear temperature representation across the thermoelectric and the cold and hot fluids respectively.

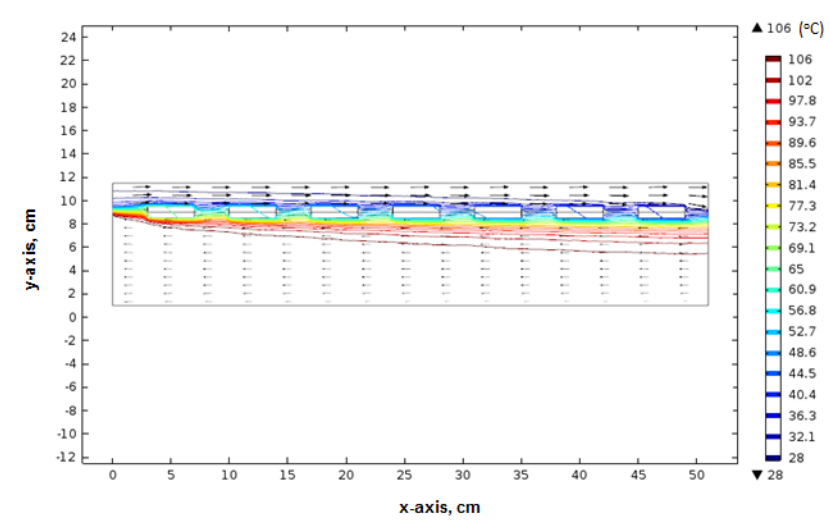

Figure 11: Vector and contour plot of the fluid flow and temperature distribution of the thermocouple array

The numerical simulation has confirmed the interaction of the heat transfer between the hot and cold fluid. It can be observed in Fig (10) that the temperature profile is more pronounced at the location $\mathrm{x}_{1}$ which is located almost at the exit of the channel. As consequence the temperature gradient across the thermoelectric is also the greatest one. The temperature increment at these different places is also noticed clearly in Figure (10). The cold fluid increases it temperature gradually. The behaviour of the temperature profile is different than a typical heat exchanger where there is a significant heat transfer across the solid material. In typical heat exchangers the thermal conductivity of the material are greater compared to the material of a thermoelectric. The presence of the foam along the channel helps to reduce the sudden increase in temperature between the fluids.

\section{CONCLUSION}

In summary, it was found that the heat transfer across the thermoelectric affected the temperature gradient between the inlet and outlet flow of hot air in the channel. The numerical simulation indicates a steady transfer of heat from the hot to the colder zone. Although the heat exchange between the fluids, this particular system does not behave as a typical heat exchanger. The results suggest that is possible to use this configuration to obtain electric energy from a hot-cold fluid interaction. It was demonstrated that the thermoelectric array absorbs heat through the process and then, in order to reach the steady state, it liberates the energy to the colder fluid. This effect may increase the outlet temperature meaning a decrease in the temperature difference.

\section{REFERENCES}

[1] Zhiting Tian, Sangyeop Lee, G. C., 2014, "Heat transfer in thermoelectric materials and devices". Heat Transfer Journal, ASME.org.

[2] B.V.K. Reddy, Matthew Barry, J. L. M. K. C., 2014. "Convective heat transfer and contact reistances effects on performance of conventional and composite thermoelectric device". Heat Transfer Journal, ASME.org, May. 5 Copyright c 2014 by ASME 
[3] Cengel, Y. A., and Boles, M. A., 1994. "Thermodynamics: An engineering approach., mcgrawhill”. Inc. New York.

[4] Joao Paulo Carmo, Luis Miguel Goncalves, J. H. C. "Thermoelectric microconverter for energy harvesting systems". IEEE TRANSACTIONS ON INDUSTRIAL ELECTRONICS

13 ${ }^{\text {th }}$ LACCEI Annual International Conference: "Engineering Education Facing the Grand Challenges, What Are We Doing?" July 29-31, 2015, Santo Domingo, Dominican Republic 